\title{
Liver Peroxisome Damage during Acute Hepatic Failure in Partial Ornithine Transcarbamylase Deficiency
}

\author{
PIERRE LANDRIEU, BAUDOUIN FRANÇOIS, ${ }^{(32)}$ GILLES LYON, AND FRANÇOIS VAN HOOF \\ Neuropediatric Department and International Institute of Cellular and Molecular Pathology, Université de Louvain, \\ B-I200 Bruxelles, Belgium
}

\begin{abstract}
Summary
A boy with ornithine transcarbamylase (OTC) deficiency was relatively symptom free for 9 months and then developed an acute episode with liver failure and metabolic imbalance. Subsequently there was severe cerebral atrophy.

Liver ornithine transcarbamylase activity was $3 \%$ of the normal mean. Of considerable interest was the finding of an accelerated breakdown of liver peroxisomes during the acute phase.

\section{Speculation}

The present observation suggests that damage to peroxisomes may be an element in acute liver dysfunction. Consequently, hypolipidaemic drugs that stimulate the production or regeneration of peroxisomes could possibly be of therapeutic interest in such conditions.
\end{abstract}

Current studies in the field of metabolic disorders should, in addition to the biochemical analyses leading to the unraveling of the modified enzyme, include if possible ultrastructural studies of the subcellular compartment in which this enzyme is normally located.

In a boy with partial ornithine transcarbamylase deficiency, we wish to report the surprising finding of an accelerated peroxisomal breakdown associated with acute liver failure. Mitochondria were not significantly altered.

\section{MATERIALS AND METHODS}

Case report. A 9-month-old boy was transfered to our University Hospital with a 7 days history of vomiting, seizures and diminished consciousness, associated with an acute otitis. He was the first child of unrelated parents and was born after uneventful pregnancy and a normal delivery. His development before the acute episode was normal. On arrival, physical examination showed a deeply comatous infant with generalized seizures and bilateral pyramidal signs. He was given phenobarbital at a daily dose of 5 $\mathrm{mg} / \mathrm{kg}$, with partial relief of his convulsions. Glycemia, blood electrolytes, cerebrospinal fluid (CSF) and tests for liver function including transaminases (SGPT, SGOT) and prothrombine time were within normal values. Plasma amino acids revealed an elevation of glutamine $(1.015 \mu \mathrm{M}$, Normal, $<700 \mu \mathrm{M})$ and alanine (940 $\mu \mathrm{M}$, Normal, $<650 \mu \mathrm{M})$.

Under high caloric and normal protein intake associated with the parenteral administration of an inverted sucrose solution ( 150 $\mathrm{mg} / \mathrm{kg}$ per $\mathrm{h}$ of fructose during $50 \mathrm{~h}$ ), the child's condition worsened. The second day after his arrival he was given $100 \mathrm{mg} /$ $\mathrm{kg} /$ day of sodium valproate and this treatment was continued thereafter. At the time this new drug was added, there were already high levels of orotic acid in the urine, and hyperaminoaciduria was present (Table 1). After the 5 th day, the blood ammonia rose from $59 \mu \mathrm{M}$ to $406 \mu \mathrm{M}$ (Normal, 20-60 $\mu \mathrm{M}$ ) and serum glutamic pyruvic transaminase reached 1200 U/liter. Prothrombine time fell to $28 \%$ of normal.

Protein and fructose intake were then stopped and, after a peritoneal dialysis, the clinical condition improved rapidly. Proteins were progressively reintroduced (maximum $2 \mathrm{~g} / \mathrm{kg}$ per day). Postprandial blood ammonia remained below $90 \mu \mathrm{M}$ (Fig. 1). A needle biopsy of the liver was performed both during the acute phase and 1 month after recovery from hepatic failure for biochemical and morphologic studies.

Although the child gained weight normally under a diet containing approximately $2 \mathrm{~g}$ protein $/ \mathrm{kg}$ per day his neurologic condition remained catastrophic. Seizures were numerous. Successive CAT scans showed a progressive atrophy of the cortex with enlargement of the ventricles. The child died at the age of $3 \frac{1}{2}$ years after an acute bronchiolitis.

A careful inquiry revealed that the mother had always had a repulsion for meat and showed signs of protein intolerance.

A brother, born subsequently, was affected with the same type of ornithine transcarbamylase deficiency diagnosed after a liver biopsy. Dietary protein has been restricted since birth and the child is normal at the time of this report. He is now aged 29 months. At the age of 9 months, he was challenged with an oral protein diet. After $2.5 \mathrm{~g}$ protein $/ \mathrm{kg}$, blood ammonia rose from $35 \mu \mathrm{M}$ up to $280 \mu \mathrm{M}$ and orotic acid increased dramatically in the urine ( $4 \mathrm{mmole} / \mathrm{g}$ of creatinine; Normal below $30 \mu \mathrm{mole} /$ g).

Material and methods. Aminoacids were determined by single column ion exchange chromatography by means of a Liquimat III Kontron amino acid analyser. Blood ammonia levels were determined by the Fenton method (9) and orotic acid according to the method of Bachmann (1).

The urea cycle enzymes, carbamyl-phosphate synthetase (CPS), ornithine transcarbamylase (OTC) and arginase (ARG) were assayed on frozen liver biopsies $\left(-60^{\circ} \mathrm{C}\right)$ within $2 \mathrm{wk}$ by methods previously described $(15,22)$. Informed consent was also obtained for taking a liver biopsy in the mother and the brother of the patient. Control samples consisted of frozen autopsy livers of infants and young adults obtained within $10 \mathrm{~h}$ after death and stored for $2-8 \mathrm{wk}$ at $-60^{\circ} \mathrm{C}$ before assay.

Light and electron microscopic studies were performed on the first biopsy during the acute stage of the disease. Morphometric analysis of electron micrographs was made according both to Delesse's (7) and Wicksell's principles $(26,27)$, using the procedure and computer programme developed by Baudhuin (2). For the latter study, liver samples from three controls (children wrongly suspected to suffer from glycogenosis) were processed.

\section{RESULTS}

Biochemical investigations. The activity of OTC in the liver of both children and the mother was less than $3 \%$ of the normal 
Table 1. Activities of urea cycle enzymes in liver of the proband and his mother ${ }^{1}$

\begin{tabular}{lcccc}
\hline Subject & $\begin{array}{c}\text { Carbamyl-phosphate } \\
\text { synthetase }\end{array}$ & $\begin{array}{c}\text { Ornithine } \\
\text { transcarbamylase }\end{array}$ & Arginase & $\begin{array}{c}\text { mg of protein/g } \\
\text { wet wt of liver }\end{array}$ \\
\hline Biopsy & & & & \\
1 & 19.5 & 18.2 & 9,190 & 134 \\
2 & & 7.4 & 4,804 & 116 \\
Mother & & 13.9 & 10,610 & 360 \\
Brother & $28 \pm 8(6)^{2}$ & $541 \pm 116(45)^{2}$ & $8,900 \pm 1,200(12)^{2}$ & 185 \\
Controls & & 54.2 & \\
\hline
\end{tabular}

${ }^{1}$ All activities are expressed as nmoles of product formed per min per mg protein.

${ }^{2}$ Mean \pm 1 S.D. (number of observations)

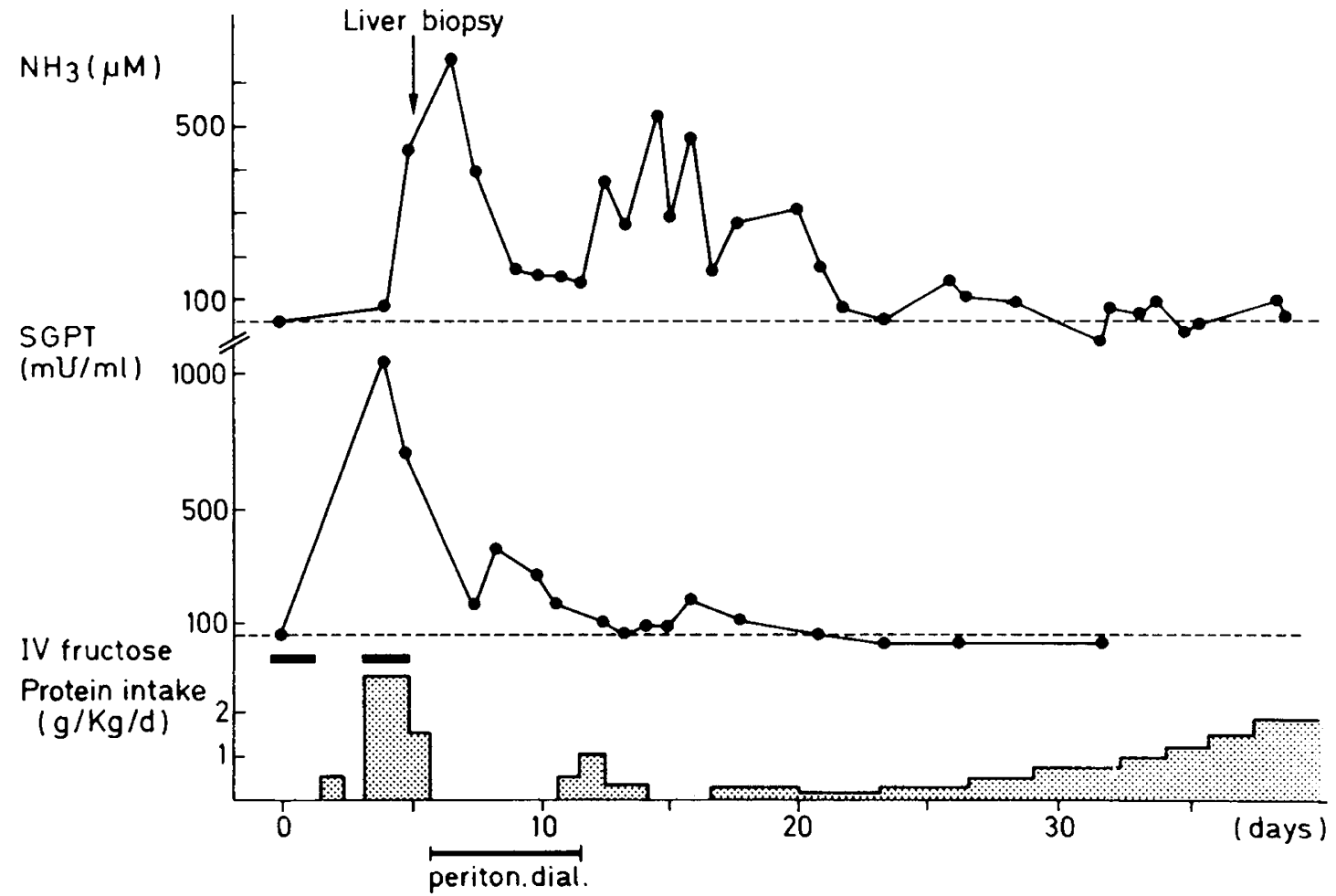

Fig. 1. Evolution of the main biologic parameters during the acute episode.

value, whereas other urea cycle enzymes were normally active (Table 1$). \mathrm{Km}$ values for ornithine $(0.79 \mathrm{mM})$ and carbamylphosphate $(0.65 \mathrm{mM})$ were within the range previously determined on four normal livers $(0.40 \pm 0.18 \mathrm{mM}$ and $0.52 \pm 0.21 \mathrm{mM}$, respectively). No shift of the optimum $\mathrm{pH}$ to alkaline values was observed. Urinary organic acids were evaluated to exclude an organic aciduria as a cause of hyperammonemia (Table 2). After recovery, orotic aciduria remained between $150-340 \mu \mathrm{mole} / \mathrm{g}$ of creatinine with a diet containing $2 \mathrm{~g}$ protein $/ \mathrm{kg}$ weight per day.

Morphologic studies. Examined with the light microscope, the hepatic parenchyma displayed numerous necrotic foci predominating in the centrolobular region. Portal areas were normal with no sign of inflammation. With the electron microscope, the most apparent change in the best preserved zones was an accumulation of fat droplets in the cytoplasm and sometimes in the nucleus of hepatocytes. More careful examination showed peroxisomal profiles to be $40 \%$ scarcer than in controls. Some of these organelles appeared enlarged with a less osmiophilic matrix showing an irregular texture (Fig. 2). A few mitochondria presented an unusual radial arrangement of the cristae.

Micrographs from the better preserved zones were submitted to a morphometric analysis, which allowed us to quantify the ultrastructural alterations and to confirm that only the amount of fat droplets (1.5\% of the cell volume, i.e., 2.1 times the controls) and the peroxisomes were significantly different from the controls. Wicksell's calculation, which allows the tridimensional reconstruc- tion of rounded organelles, demonstrated clearly the bimodal distribution of the peroxisomal population (Fig. 3). Table 3 summarizes the morphometric data obtained for peroxisomes. In the patient, the two populations were considered separately. The proliferation of the smaller peroxisomes with a normal matrix was found predominantly in cells with fewer fat droplets. Conversely the larger peroxisomes with an inhomogeneous matrix belonged mostly to cells rich in lipids, and were 4.5 times more frequently surrounded by elements of the rough endoplasmic reticulum, which suggests (8) that they were undergoing an autophagic sequestration (Fig. 2). The maximum volume of the latter population was approximately 3 times greater than in controls.

\section{DISCUSSION}

Among inborn defects of urea cycle enzymes, OTC deficiency appears to be the most frequent (14). Delayed clinical evidence of the resulting metabolic imbalance, as seen in our patient, has been reported in boys with partial OTC deficiency $(16,29)$, but the occurrence of acute liver disease in this condition is a puzzling feature. To account for it, the simultaneous occurrence of several precipitating factors such as a febrile episode, a high protein intake and the administration of fructose in the maintenance perfusion might be incriminated. It is noteworthy that fructose infusion causes a rapid depletion in hepatic triphosphonucleotides $(5,25)$ and that the urea cycle activity is closely linked to the ATP level 
in the cell (4). A somewhat similar acute liver failure has been reported in a presumed heterozygote for OTC deficiency after extensive use of an insect repellent, N,N-diethyltoluamide (12). Long term therapy with sodium valproate is also known to induce hyperammonemia $(6,10)$. It seems, however, unlikely that this product played an important role here. Indeed, it was given when there were already evident signs of liver dysfunction, and did not prevent the recovery from the metabolic imbalance.

Table 2. Amino acids and organic acids in urine $(\mu \mathrm{mole} / G$ (reatinine)

\begin{tabular}{lrrc}
\hline & On day 2 & On day 3 & $\begin{array}{c}\text { Normal values } \\
\text { range }\end{array}$ \\
\hline Alanine & 5022 & 19,145 & $30-670$ \\
Glutamic acid & 755 & 230 & $5-85$ \\
Glutamine & 8667 & 745 & $45-845$ \\
Glycine & 5333 & 10,060 & $890-4450$ \\
Tyrosine & 1378 & 2 & $55-160$ \\
Lactate & 10,000 & 30,700 & $<500$ \\
2-OH-butyrate & 2 & 3920 & 2 \\
3-OH-butyrate & 7400 & 11,000 & $<2000$ \\
3-OH-isovalerate & 2400 & 2800 & $<500$ \\
3-OH-propionate & traces & traces & 2 \\
Adipate-suberate & traces & traces & $<50$ \\
Orotic acid & 18,025 & 1195 & $0.4-25$ \\
\hline
\end{tabular}

'Only significant data are reported.

${ }^{2}$ Less than $0.1 \mu \mathrm{mole} / \mathrm{ml}$.
Morphologic alterations of liver cells in patients with partial or total OTC deficiency are as a rule minimal and without obvious biologic consequences $(16,21)$. Mitochondrial changes, as described by Shapiro et al. (20) in the liver of a child who was heterozygous for OTC deficiency, have not been found in our case. Also, there are striking differences between the morphologic lesions found in our patient and in Reye's syndrome, in which steatosis is massive and mitochondria are severely altered (19).

Only a few cases of OTC deficient livers have been studied with the electronmicroscope and qualitative or quantitative abnormalities of peroxisomes have not been previously reported. There was an increase in the number and size of peroxisomes in a case of hyperammonemia with hyperornithinemia and homocitrullinemia (28). A profound diminution of the number of peroxisomes is known to exist in Zellweger's hepato-cerebro-renal syndrome (11).

Peroxisomes contain several hydrogen peroxide generating enzymes including D-aminoacid oxidase, L-alpha-hydroxyacid oxidase, fatty acid beta oxidase (17) and also catalase, an enzyme capable of converting hydrogen peroxyde directly to water and oxygen. Present knowledge on this organelle has been reviewed by Baudhuin (3) and Masters and Holmes (18).

In our patient there is striking evidence for a pathologic process involving predominantly peroxisomes, whereas mitochondrial changes are minimal. Isolated signs of breakdown or of regeneration of peroxisomes are seen in hepatocytes that otherwise remain well preserved or with little lipid accumulation. Moreover, there is a correlation between the importance of peroxisomal lesions and the degree of damage to hepatocytes, prenecrotic cells being almost completely deprived of these organelles.

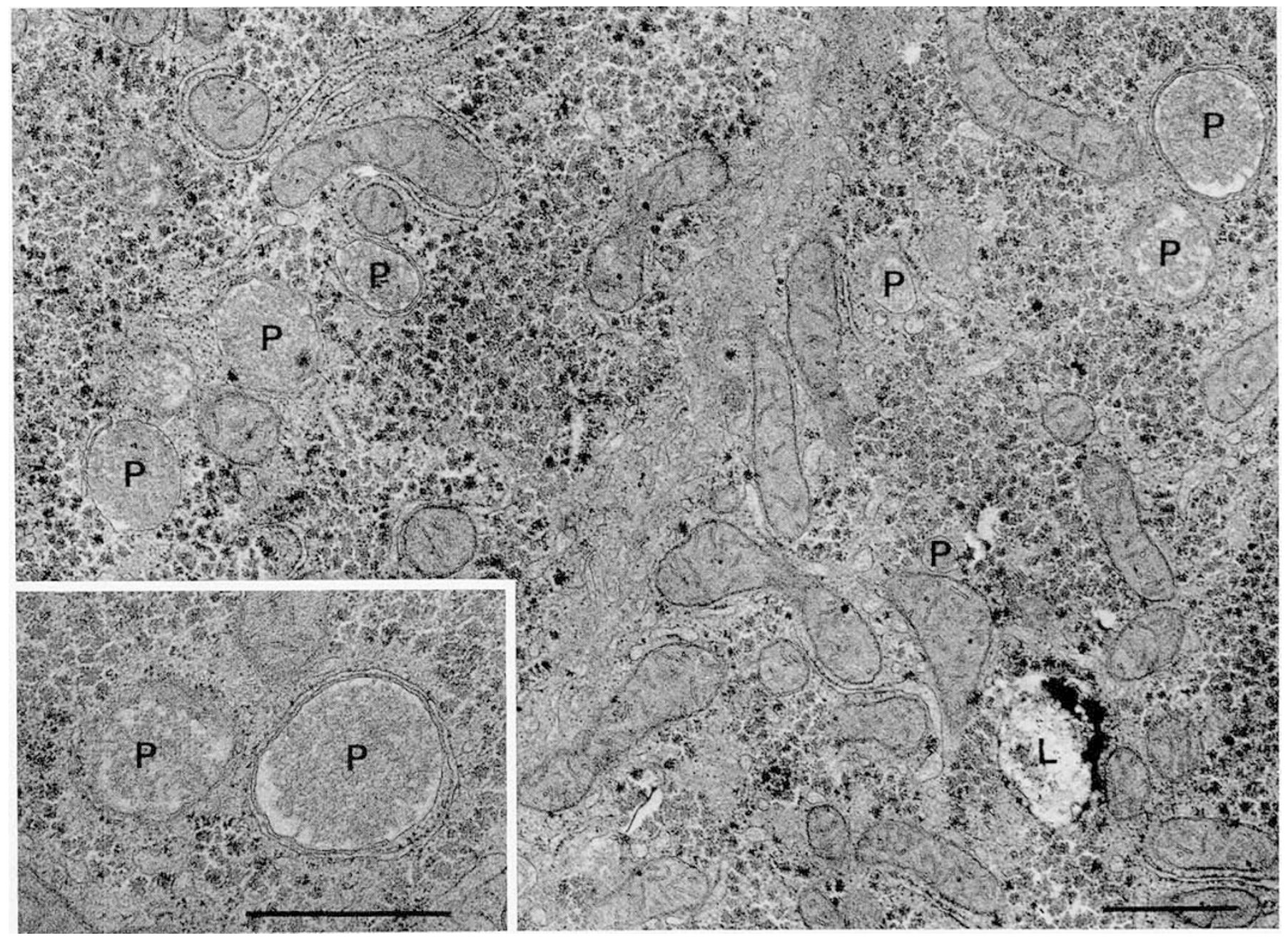

Fig. 2. Morphology of the peroxisomes in hepatocytes (magnification $\times 18,850$ ). In the inset (magnification $\times 28,650$ ), the peroxisome on the right is surrounded by rough endoplasmic reticulum, suggesting an autophagic process. The bar scale is $1 \mu \mathrm{m}$ long. (P, peroxisomes; $\mathrm{L}$, lipid inclusion). 

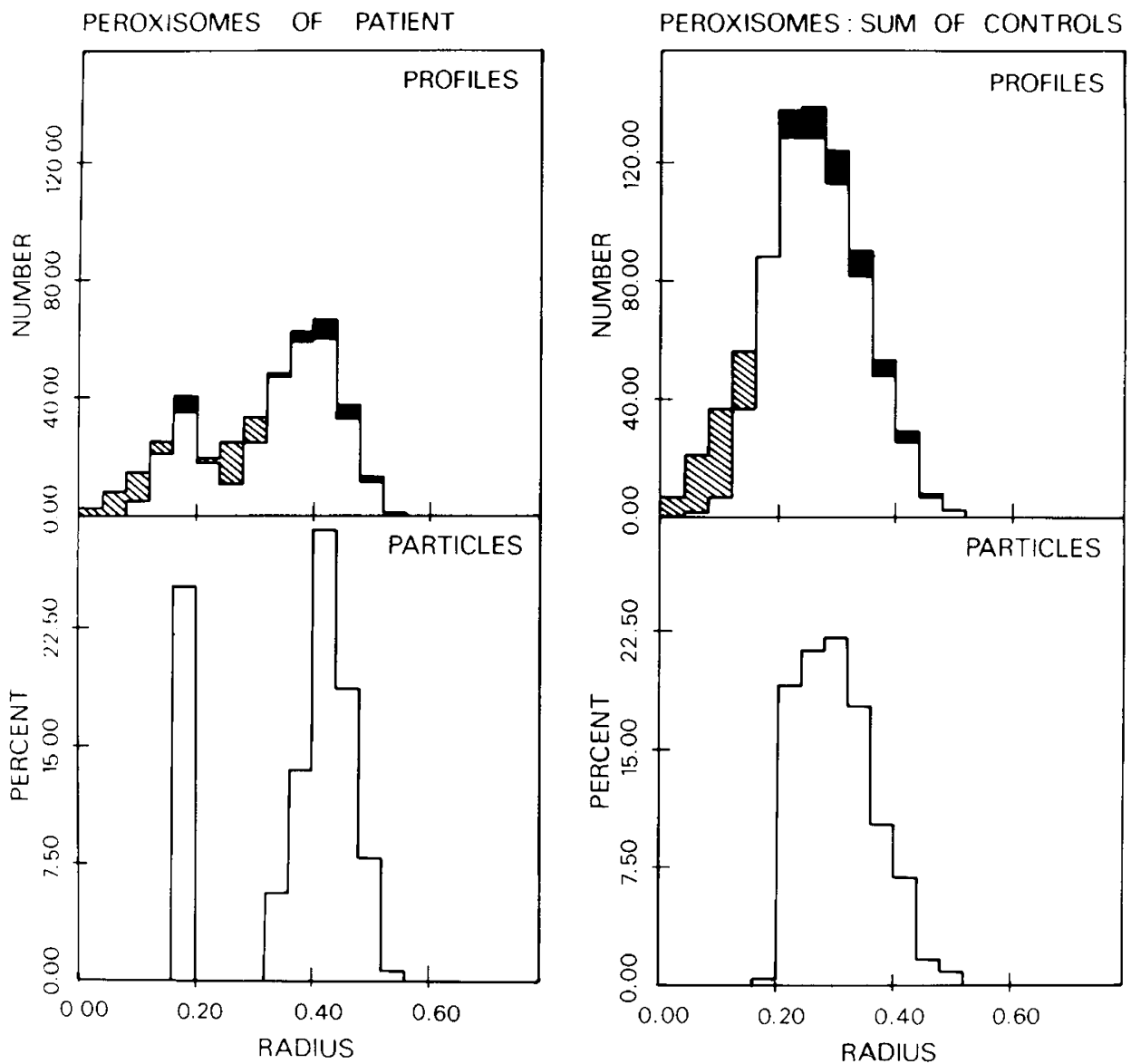

Fig. 3. Size distribution of peroxisomes in the patient and controls. Upper histograms including black area represent the observed distribution of profiles. The actual size distribution of the peroxisomes was calculated according to Wicksell (lower histograms), after correction for section thickness (subtraction of black area) and addition of hatched area to account for the small polar unidentified profiles. Identification criteria for peroxisomes were those of Baudhuin (3).

Table 3. Quantitative data on liver peroxisomes

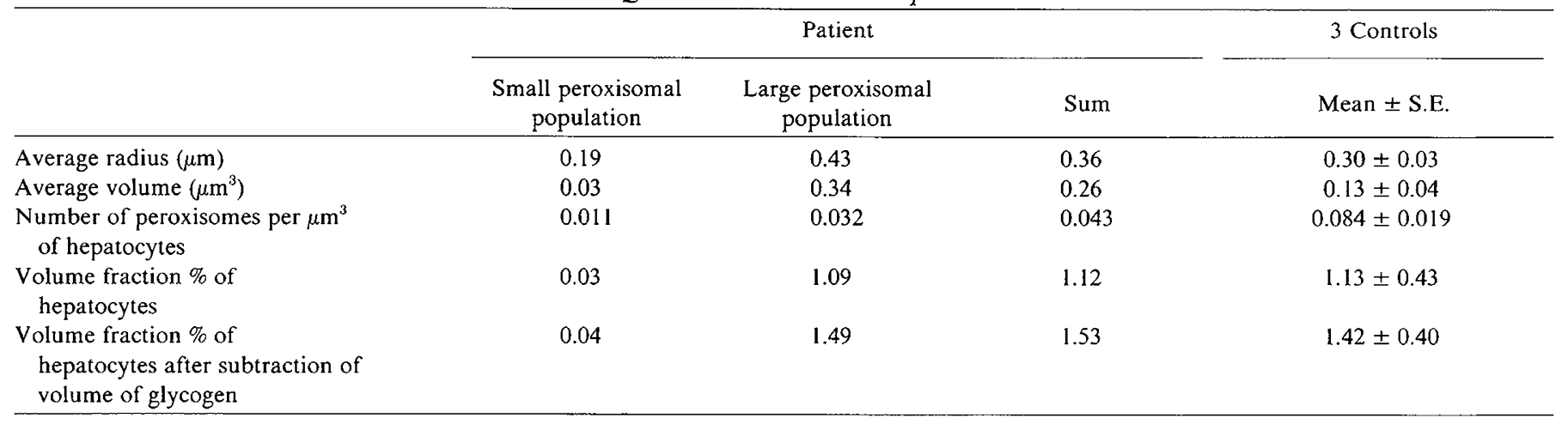

This raises the possibility that a damage to peroxisomes could have played a role in producing acute liver failure in this patient; however, the relation between peroxisomal lesions and dysfunction of liver cells remains hypothetical, as the biologic role of peroxisomes in the liver cell is still incomplete $(3,18)$, and because little attention has been given to the morphology of peroxisomes in other cases of acute liver failure. The changes in peroxisomes (which are not found in the liver of the brother) are unlikely to be specifically related to the OTC deficiency.

Toxic substances are liable to induce comparable changes. In hepatocytes of animals receiving hypoglycin or pent-4-enoate which are substances known to interfere with the beta-oxidation of short chain fatty acids (13), there is a swelling of peroxisomes followed by their disappearance. In addition there is a swelling of mitochondria and accumulation of fat droplets.

It is remarkable that the previous administration of clofibrate,
[2-(4 chlorophenoxy)-2-methylpropanoic acid ethyl ester] which is known to induce peroxisomal proliferation and to stimulate the beta-oxidation of fatty acids in these organelles, largely protects the animals from the toxicity of these drugs (23). The protective action of clofibrate is obtained only after $2-4$ wk in rats, which would make the use of this drug inefficient in an acute liver failure. But clofibrate is certainly not the only potentially interesting drug. In animals, we have obtained approximately the same protection against pent-4-enoate, by replacing clofibrate by nafenopin (SU-13.437 from CIBA) and this after 2-4 days (24). The latter drug is known to induce hepatomas in rodents when given over long periods, but for short period the carcinogenic effects would probably be negligible. In acute liver involvement, short term administration of the product could be an acceptable procedure in order to diminish the risk of severe hepatic lesions and possibly irreversible brain damage. 
It seems reasonable to postulate that peroxisomal damage in acute human liver disease might have been overlooked and that its occurrence is not exceptional. The importance of future evaluating the role of peroxisomes in such conditions is enhanced by the prospect of a therapeutic approach.

\section{REFERENCES AND NOTES}

1. Bachmann, C.: Urea cycle. In: W.L. Nyhan, Ed.: Heritable disorders of aminoacid metabolism. pp. 361-386 (Wiley, New York, 1974).

2. Baudhuin, P.: Morphometry of subcellular fractions. Methods Enzymol., 32B: pp. 3-20 (Academic Press, New York, 1974).

3. Baudhuin, P.: Peroxisomes (microbodies, glyoxysomes). In: A. Lima-de-Faria Ed.: Handbook of Molecular Cytology, 15: pp. 1179-1195 (Amsterdam: North Holland. 1969)

4. Bessman, S. P. and Pal, N.: The Krebs cycle depletion, theory of hepatic coma. In: S. Grisolia, R. Baguena, F. Mayor, Eds.: The urea cycle, pp. 83-89 (Wiley, New York, 1976).

5. Bode, J. C., Zelder, Ö., Rumpelt, H. J., and Wittkamps, U.: Depletion of liver adenosine phosphate and metabolic effects of intravenous infusion of fructose or sorbitol in man and in the rat. Eur. J. Clin. Invest., 3: 436 (1973).

6. Coude, F. X., Rabier, D., Cathelineau, L., Grimberg, G., Parvy, P., and Kamoun, P. P.: A mechanism for Valproate-induced hyperammonemia. Pediatr. Res., 15: 974 (1981)

7. Delesse, A.: Procédé mécanique pour déterminer la composition des roches. Compt. Rend. Acad. Sci., 25: 544 (1847).

8. Ericsson, J. L. L.: Mechanism of cellular autophagy. In: J. T. Dingle and H. B. Fell, Eds.: Lysosomes in Biology and Pathology. pp. 345-394 (Amsterdam: North Holland, 1969).

9. Fenton, J. C.: The estimation of plasma ammonia by ion exchange. Clin. Chim. Acta, 7: 163 (1962)

10. Gerber, N., Dickinson, R. G., Harland, R. L., Lynn, R. K., Houghton, D., Antonias, J. T., and Schimschock, J. L.: Reye-like syndrome associated with Valproic acid therapy. J. Pediatr., 95: 142 (1979).

11. Goldfischer, S., Moore, C. L., Johnson, A. B., Spiro, A. J., Valsamis, M. P., Wisniewski, H. K., Ritch, R. H., Norton, W. T., Rapin, I., and Gartner, L. M.: Peroxisomal and mitochondrial defects in the cerebro-hepato-renal syndrome. Science (Wash. D.C.), 182: 62 (1973).

12. Heick, H. M. C., Shipman, R. T., Norman, M. G., and James, W.: Reye-like syndrome associated with use of insect repellent in a presumed heterozygote for ornithine carbamoyl transferase deficiency. J. Pediatr., 97: 471 (1980).

13. Holland, P. C. and Sherratt, H. S. A.: Biochemical effects of the hypoglycaemic compound pent-4-enoic acid and related non-hypoglycaemic fatty acids. Effects of the free acids and their carnitine esters on coenzyme A-dependent oxidations in rat liver mitochondria. Biochem. J., 136: 157 (1973).

14. Hsia, Y. E.: Inherited hyperammonemic syndromes. Gastroenterol., 67: 347 (1974).

15. Kalousek, F., François, B., and Rosenberg, L. E.: Isolation and characterization of ornithine transcarbamylase from normal human liver. J. Biol. Chem., 253:
3939 (1978).

16. Krieger, I., Snodgrass, P. J., and Roskamp. I.: Atypical clinical course of ornithine transcarbamylase deficiency due to a new mutant (comparison with Reye's disease). J. Clin. Endo. Metab., 48: 388 (1979)

17. Lazarow, P. B. and de Duve, C.: A fatty acyl-CoA oxiding system in rat liver peroxisomes: enhancement by Clofibrate, a hypolipidemic drug. Proc. Natl. Acad. Sci. USA, 6: 2043 (1976).

18. Masters, C. and Holmes, R.: Peroxisomes: new aspects of cell physiology and biochemistry. Physiological Reviews, 57: 816 (1977).

19. Partin, J. C., Schubert, W. K., and Partin, J. S.: Mitochondrial ultrastructure in Reye's syndrome (Encephalopathy and fatty degeneration of the viscera). N Engl. J. Med., 285: 1339 (1971).

20. Shapiro, J. M., Schaffner, F., Tallon, H. H., and Gaull, G. E.: Mitochondrial abnormalities of liver in primary ornithine transcarbamylase deficiency. Pediatr. Res., 14: 735 (1980).

21. Shih, V. E.: Urea cycle disorders and other congenital hyperammonemic syndromes. In: J. B. Stanbury, J. B. Wyngaarden, D. S. Fredrickson, Eds.: The Metabolic Basis of Inherited Disease, pp. 362-386 (McGraw-Hill, New York, 4th Edition, 1978).

22. Snodgrass, P. J.: The effect of $\mathrm{pH}$ on the kinetics of human liver OTC. Biochemistry, 7: 3047 (1968).

23. Van Hoof, F., Hue, L., Sherratt, S. A.: Protection of rats against hypoglycin and pent-4-enoate toxicity by pretreatment with Clofibrate. Biochem. Soc. Transactions, 7: 163 (1979).

24. Van Hoof, F. and Sherratt, H. S. A. (unpublished data).

25. Van den Berghe, G, and Hers, H. G.: Dangers of intravenous fructose and sorbitol. Act. Paediat. Belg., 31: 115 (1978).

26. Wicksell, S. D.: The corpuscle problem, a mathematical study of biometric problem. Biometrika, 17: 84 (1925).

27. Wicksell, S. D.: The corpuscle problem. Second memoir. Case of ellipsoidal corpuscles. Biometrika, 18: 151 (1926).

28. Winter, H. S., Perez-Atayde, Levy, H. L., and Shih, V. E.: Unique hepatic ultrastructural changes in a patient with hyperammonemia, hyperornithinemia and homocitrullinuria (abstract). Pediatr. Res., 14: 583 (1980).

29. Yudkoff, M., Yang, W., Snodgrass, P. J., and Segal, S.: Ornithine transcarbamylase deficiency in a boy with normal development. J. Pediatr., 96: 441 (1980).

30. This study was performed with the informed consent of the parents.

31. The authors would like to thank Dr. P. Baudhuin, Dr. S. Gosseye for their precious help and Dr. C. Bachmann, Bern University, Switzerland for the organic acid determination; the expert assistance of Mrs. B. Lederer, Mrs. D. Gyselen, Mr. G. Braud and Mr. M. Thillaye was much appreciated and is duly acknowledged.

32. Requests for reprints should be addressed to: Baudouin François, M.D., Neuropaediatric Department, U.C.L. 10/1303, Avenue Hippocrate, 10 B-1200 Bruxelles (Belgium).

33. This research was supported in part by the Belgian Fonds National de la Recherche Scientifique Médicale, grants 3.4513 .76 and 3.4547 .79 and the U.S. Public Health Service grant AM 9235

34. Received for publication May 18, 1981.

35. Accepted for publication February 5, 1982. 